\title{
Imipenem resistance of Pseudomonas in pneumonia: a systematic literature review
}

Marya D Zilberberg ${ }^{1,2^{*}}$, Joyce Chen ${ }^{3}$, Samir H Mody ${ }^{3}$, Andrew M Ramsey², Andrew F Shorr ${ }^{4}$

\begin{abstract}
Background: Pneumonia, and particularly nosocomial (NP) and ventilator-associated pneumonias (VAP), results in high morbidity and costs. NPs in particular are likely to be caused by Pseudomonas aeruginosa (PA), 20\% of which in observational studies are resistant to imipenem. We sought to identify the burden of PA imipenem resistance in pneumonia.

Methods: We conducted a systematic literature review of randomized controlled trials (RCT) of imipenem treatment for pneumonia published in English between 1993 and 2008. We extracted study, population and treatment characteristics, and proportions caused by PA. Endpoints of interest were: PA resistance to initial antimicrobial treatment, clinical success, microbiologic eradication and on-treatment emergence of resistance of PA.

Results: Of the 46 studies identified, $20(N=4,310)$ included patients with pneumonia (imipenem 1,667, PA 251; comparator 1,661, PA 270). Seven were double blind, and 7 included US data. Comparator arms included a $\beta$ lactam (17, [penicillin 6, carbapenem 4, cephalosporin 7, monobactam 1]), aminoglycoside 2, vancomycin 1, and a fluoroquinolone 5; 5 employed double coverage. Thirteen focused exclusively on pneumonia and 7 included pneumonia and other diagnoses. Initial resistance was present in 14.6\% (range 4.2-24.0\%) of PA isolates in imipenem and $2.5 \%$ (range $0.0-7.4 \%$ ) in comparator groups. Pooled clinical success rates for PA were $45.2 \%$ (range $0.0-72.0 \%$ ) for imipenem and $74.9 \%$ (range $0.0-100.0 \%$ ) for comparator regimens. Microbiologic eradication was achieved in $47.6 \%$ (range $0.0 \%-100.0 \%$ ) of isolates in the imipenem and $52.8 \%$ (range $0.0 \%-100.0 \%$ ) in the comparator groups. Resistance emerged in 38.7\% (range 5.6-77.8\%) PA isolates in imipenem and 21.9\% (range 4.8$56.5 \%)$ in comparator groups.

Conclusions: In the 15 years of RCTs of imipenem for pneumonia, PA imipenem resistance rates are high, and PA clinical success and microbiologic eradication rates are directionally lower for imipenem than for comparators. Conversely, initial and treatment-emergent resistance is more likely with the imipenem than the comparator regimens.
\end{abstract}

\section{Background}

Antimicrobial resistance is a growing concern in the US and abroad. Among infections caused by gram-positive pathogens, methicillin-resistant Staphylococcus aureus (MRSA) has taken center stage, now accounting for well over $50 \%$ of all documented staphylococcal infections in the US [1]. Similarly, hospitalizations with vancomycinresistant enterococcal (VRE) species are rising rapidly, particularly since 2003 [2,3]. Gram negative bacteria,

\footnotetext{
* Correspondence: Marya@evimedgroup.org

'School of Public Health and Health Sciences, University of Massachusetts, Amherst, MA, USA

Full list of author information is available at the end of the article
}

though not necessarily rising in volume [3], are also becoming increasingly resistant to existing antimicrobials. Most alarming is the evolution of extended-spectrum $\beta$-lactamase producing Enterobacteriaceae, as well as multidrug resistant Pseudomonas aeruginosa (PA), some resistant to multiple drug classes [4,5].

PA in particular is reported to have $20 \%$ resistance rates to imipenem, a drug considered to be first-line therapy for ventilator-associated pneumonia, for example, and one that is frequently utilized when the suspicion of PA is high [6]. The patterns of PA resistance are important to appreciate because of the strong evidence that inappropriate empiric therapy leads to increased

\section{Biomed Central}


hospital mortality $[7,8]$, and patients with a resistant infection are less likely to receive appropriate initial treatment $[9,10]$. For this reason, starting empiric coverage with a broad-spectrum antibiotic followed by deescalation has been advocated as a strategy to improve outcomes [6]. To justify such a strategy it is important to have complete information on the epidemiology of pathogen resistance, and in the absence of a national surveillance mechanism, all potential sources of such information should be explored. While several primary epidemiologic and microbiology studies have demonstrated reduced imipenem susceptibility among PA $[4,5,11,12]$, the full burden of emerging imipenem resistance reported in the literature has not been quantified. Thus, we performed a systematic review of literature to explore and quantify emerging resistance and reduced susceptibility of PA to imipenem in the setting of pneumonia.

\section{Methods}

We conducted a MEDLINE search using keywords "pneumonia" and "imipenem" with the Boolean operator "AND" joining the two. We restricted this search to papers published in English between January 1993 and December 2008 that were randomized controlled trials, clinical trials, or meta-analyses. Two investigators reviewed all identified studies for relevance and resolved any disagreement by reaching consensus. Because we intended to document emerging trends in the development and characteristics of imipenem resistance among PA isolates, only studies utilizing one of the three specified study designs, including a pharmaceutical comparator, and mentioning both PA and imipenem were included in our analysis.

Two reviewers (AR, MDZ) extracted pertinent data from each study and entered it into data extraction forms developed specifically for the current project. Specifically, we extracted information about geographic location of study population, study period, population characteristics, characterization of therapy, blinding, and factors related to PA. Although our primary interest was PA, we documented the intended primary and secondary endpoints for each study.

Included were data from all patients with at least $1 \mathrm{PA}$ isolate receiving at least 1 dose of the specified treatment. We assumed that patients with PA isolates in studies not specifying a minimum number of antibiotic doses received at least 1 dose and included them in our analysis as well. The outcomes of interest were clinical and microbiological eradication rates for PA among the included patients, as well as initial and emerging resistance of PA to imipenem and comparator drugs, and PA superinfection rates. Wherever possible, we normalized both initial and emerging resistance to the baseline number of patients with PA isolates reported. If it was unclear whether the newly-emergent resistant PA occurred in a patient with a previous PA culture, we assumed that this was the case and utilized the total number of PA isolates reported in the denominator. Each patient was assumed to qualify for one initial or one emergent resistant PA, and thus the words "isolates" and "patients" are used interchangeably throughout this report. Finally, we collected information on adverse outcomes, including development of diarrhea in general and specifically the emergence of Clostridium difficile infection (CDI). Studies were excluded if they failed to report at least one of the outcomes of interest.

The success of PA treatment was computed by deriving the proportions of clinical and microbiological eradication across all included studies. We quantified the pooled overall percentage of PA isolates in which resistance was either present at baseline or emerged, as well as the incidence of superinfection. All outcome definitions were those used in the respective primary studies; for example, "clinical success" was defined most frequently as resolution of signs and symptoms related to the infection. We further performed sensitivity analyses in studies incorporating blinding in the experimental protocol, by drug class of the comparator therapy, in studies with nosocomial pneumonia and those performed in North America only. All pooling was performed qualitatively and no attempt at quantitative analyses was made.

\section{Results}

Of 46 papers identified in our search published between 1993 and 2008, 26 [13-38] were excluded while 20 [39-58] met the inclusion criteria. The reasons for exclusion [13-38] were as follows (Figure 1): no mention of imipenem $(n=2)[13,14]$; study designs other than controlled trials, clinical trials or meta-analyses $(n=4)$ [15-18]; failed to mention PA $(n=8)$ ([9-26]; provided incomplete quantitative information about PA $(\mathrm{n}=2)$ $[27,28]$; quantified the presence of PA isolates but did not provide useful information about their eradication or emerging resistance $(n=4)$ [29-32]; found no PA in initial cultures $(n=1)$ [33]. Additionally, 2 controlled trials assessed the efficacy of alternative imipenem dosages, and were excluded for this reason [34,35]. To avoid double counting, we ultimately excluded both of the meta-analyses [36,37], since all relevant papers examined therein had already been included, as well as one additional primary report [38] which duplicated a previously reported study [57]. One exception was made to include the study by Shorr and coworkers [44], which is a subgroup analysis of VAP patients enrolled into another study of NP in our study set [46]. This was done for the following reasons: 1). Shorr et al. [44], but not West and 


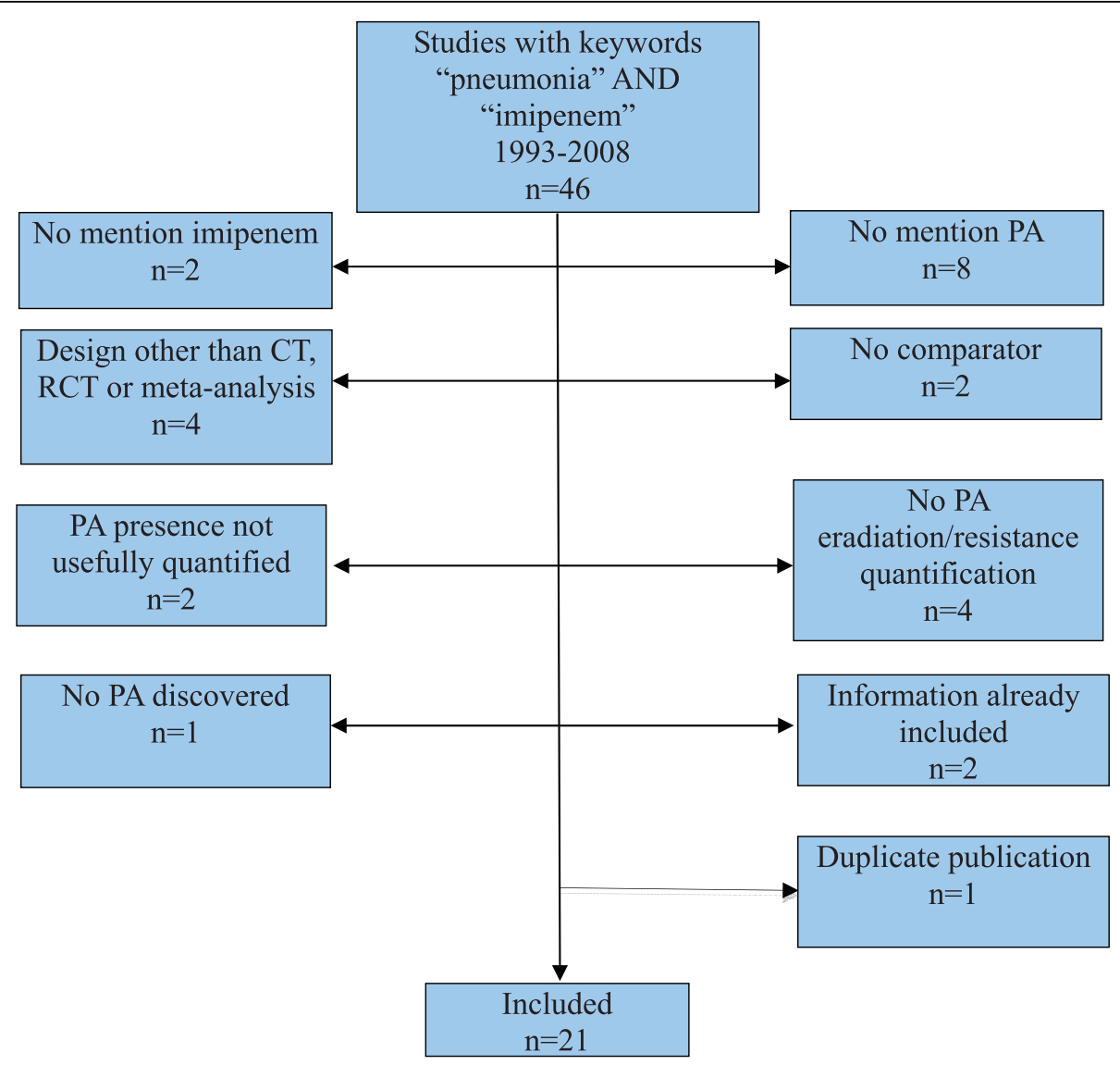

Figure 1 Study selection flow chart. PA: Pseudomonas aeruginosa; CT: clinical trial; RCT: randomized controlled trial

colleagues [46], reported on several outcomes of primary interest (specifically PA resistance emergence) in the current review, 2). Eliminating the Shorr study from the analyses did not alter the results substantively, and 3). Several of the sensitivity analyses used only one or the other of the studies, but not both (see below).

In all, 20 clinical trials comprised the final set [39-58] (Table 1). Comparator drug subcategories included a $\beta$ lactam arm in 16 studies [39-46,48-51,53,54,56,58], fluoroquinolone in 5 studies $[44,46,47,55,57]$, aminoglycoside in 2 studies [53,56], and vancomycin in 1 study [52]; 6 employed double coverage [44,45,52-54,56]. The primary outcome for 17 of these 20 studies was clinical success $[39-52,54,57,58]$ and 16 of 20 included a microbiological response assessment for underlying pathogens [39-43,45-48,50,52-54,56-58] (Table 1). Ten of 20 studies provided information about the minimum number of imipenem and comparator doses required for inclusion in analysis, 7 of which included patients if they received at least 1 dose of either imipenem or the comparator $[39,41,42,46,47,50,57]$, and 1 study each excluding patients receiving fewer than 5 [49], 6 [40], and 15 [55] doses (Table 2).
Seven of 20 studies included patients with mixed infections (pneumonia and other diagnoses) $[49,50,52-54,56,58]$, while 13 of the 20 included only patients with pneumonia [39-48,51,55,57] (Table 1): seven with NP [39,41,42,44-47], with 3 of those 7 focusing on VAP only $[39,44,47]$; 4 with community-acquired pneumonia (CAP) $[40,43,48,51]$, and two with either CAP or NP $[55,57]$. Of the 4,310 subjects analyzed in the 20 studies, 3,328 had pneumonia: 1,667 in the imipenem and 1,661 in the comparator groups. Determining accurately the exact counts of NP and VAP among the total pneumonia patient population was not feasible.

Among the 4,310 subjects, 521 grew out PA isolates in microbiological cultures, 251 in the imipenem and 270 in the comparator groups (Table 2). In 11 studies providing information about clinical PA outcomes $[39,43,44,46-49,51,52,54,58], 54$ of 120 patients in the imipenem group and 91 of 121 patients in the comparator group were considered clinically cured, with the pooled success rate of $45.2 \%$ (range $0.0 \%-72.0 \%$ ) for the imipenem and $74.9 \%(0.0 \%-100.0 \%)$ for the comparator arms. Similarly, in 11 studies providing information on PA microbiological outcomes [39,40,42,43,46-48,53,54,56,57], 72 of 
Table 1 Study characteristics.

\begin{tabular}{|c|c|c|c|c|c|}
\hline First author, year & Centers & Population & Primary endpoint & Comparator regimen & Minimum doses \\
\hline Chastre, 2008 [39] & M & VAP & C/M success & Doripenem & 1 \\
\hline Yanagihara, 2005 [40] & S & CAP & C/M success & Sulbactam/ampicillin & 6 \\
\hline Schmit, 2006 [41] & M & NP & Clinical response & Piperacillin/tazobactam & 1 \\
\hline Joshi, 2006 [42] & M & NP & Clinical response & Piperacillin/tazobactam & 1 \\
\hline Romanelli, 2006 [43] & M & CAP & C/M success & Meropenem & NR \\
\hline Shorr, 2005 [44] & M & VAP & Clinical success & Levofloxacin/ceftazidime & NR \\
\hline Zanetti, 2003 [45] & M & NP & C/M success & Cefepime & NR \\
\hline West, 2003 [46] & M & NP & C/M success & Levofloxacin/ceftazidime & 1 \\
\hline Torres, 2000 [47] & M & VAP & C/M success & Ciprofloxacin & 1 \\
\hline Bartoloni, 1999 [48] & M & CAP & Clinical response & Meropenem & \\
\hline Jaccard, 1998 [49] & M & Mixed & Clinical success & Piperacillin/tazobactam & 5 \\
\hline Marra*, 1998 [50] & $\mathrm{S}$ & Mixed & $\mathrm{C} / \mathrm{M}$ success, resistance & Piperacillin/tazobactam & 1 \\
\hline Ho, 1997 [51] & NR & CAP & Clinical success & Ceftazidime & $N R$ \\
\hline Raad, 1996 [52] & S & Mixed & C/M success & Aztreonam/vancomycin & NR \\
\hline Vic, 1996 [53] & $\mathrm{S}$ & Mixed & Bacteriological parameters & Ceftazidime/amikacin & NR \\
\hline Bohme, 1995 [54] & NR & Mixed & C/M success & Ceftazidime/piperacillin & NR \\
\hline Siami, 1995 [55] & M & CAP \& NP & Safety & Ciprofloxacin & 15 \\
\hline Cometta, 1994 [56] & M & Mixed & Tolerance & Imipenem/netilmycin & NR \\
\hline Fink, 1994 [57] & M & CAP \& NP & C/M success & Ciprofloxacin & 1 \\
\hline Norrby, 1993 [58] & M & Mixed & C/M success & Ceftazidime & NR \\
\hline
\end{tabular}

M: multicenter, S: single center, NR: not reported, C/M: clinical/microbiological, VAP: ventilator-associated pneumonia, CAP: community-acquired pneumonia, ICU: intensive care unit, NP: nosocomial pneumonia, NR: not reported, CF: cystic fibrosis, PA: Pseudomonas aeruginosa

*Although this study did not explicitly report on PA outcomes, it was included because it was one of the few studies specifically reporting zero incidence of $C$. difficile diarrhea

$151,47.6 \%$ (range $0.0 \%-100.0 \%$ ), of isolates in the imipenem group were successfully eradicated, while 90 of 171 , $52.8 \%$ (range $0.0 \%-100.0 \%$ ), of isolates in the comparator group were eliminated. Three studies $[39,45,49]$ reporting initial PA treatment sensitivities found 12 of $81,14.6 \%$ (range $4.2 \%-24.0 \%$ ) of isolates in the imipenem arm and 2 of $76,2.5 \%$ (range $0.0 \%-7.4 \%$ ) of isolates in the comparator that were resistant to the initial treatment. In 9 studies reporting the emergence of resistance to the initial antimicrobial among PA isolates $[39,44,45,47,49,55-58]$, resistance to imipenem developed in 78 of 202, 38.7\% (range $5.6 \%-77.8 \%$ ) instances in the imipenem group and 45 of $204,21.9 \%$ (range $4.8 \%-56.5 \%$ ) in the comparator treatment group. Data on the rates of PA superinfection could not be collected reliably. Neither information on average duration of therapy prior to resistance nor the minimum inhibitory concentration (MIC) for imipenem was reported consistently. Although there appeared to be a directional increase in baseline resistance rate of PA to imipenem over time (Figure 2), examining treatmentemergent resistance rates over time did not reveal any clear directional trends (Figures 3).

While adverse events were reported to some extent in nearly every study, the attribution of causation to the respective treatment was rare. Nine of the 21 included studies reported emergence of diarrhea as an adverse event in 104 of 1,576 patients in the imipenem group, $6.6 \%$ (range
$2.7 \%-18.1 \%$ ), and 145 of 1,563 patients in comparator group, 9.3\% (range 1.0\%-29.3\%) [39,41,42,45,46,49,50,52,58]. Only 3 of these 9 studies reported CDI emergence, which was noted in 6 of 334 (1.8\%, range $0.0 \%-5.9 \%$ ) imipenemtreated patients and 2 of 335 (0.6\%, range $0.0 \%-1.1 \%)$ comparator-group patients $[45,50,52]$.

\section{Sensitivity analyses \\ Blinding}

Seven of 20 studies incorporated blinding, 4 of 7 using double-blinding $[42,50,55,57]$ and 3 using investigatorblinding only $[41,52,58]$ (Table 3 ). Only 2 of these 7 studies [42,57] reported microbiologic eradication of PA, with the aggregate rate of 29 of $61,47.8 \%$ (range $25.0 \%$ $70.6 \%$ ) and 34 of $65,52.1 \%$ (range $27.7 \%-76.5 \%$ ) in the imipenem and comparator groups, respectively [42,57]. Further, only 2 of the 7 blinded studies $[52,58]$ provided information on PA clinical success, where the rates of this outcome were 3 of $15,21.1 \%$ (range $0.0 \%-42.1 \%$ ), in the imipenem group and 16 of $20,78.7 \%$ (range $75.0 \%$ $82.4 \%$ ), in the comparator group. While none of the studies in this group reported baseline resistance rates, in 3 blinded studies reporting emerging resistance $[55,57,58]$, the rates for this outcome were 38 of $67,56.9 \%$ (range $42.9 \%-77.8 \%$ ) and 19 of $75,25.3 \%$ (range $6.3 \%-41.7 \%$ ), of imipenem and comparator group PA isolates, respectively. 
Table 2 Results: $P$. aeruginosa clinical and microbiologic success, baseline and emergent resistance rates*

\begin{tabular}{|c|c|c|c|c|c|c|}
\hline First author, year & Study arm & $\begin{array}{r}\text { PA isolates } \\
(\mathrm{n})\end{array}$ & $\begin{array}{r}\text { Clinical success } \\
(\%) \\
\end{array}$ & $\begin{array}{r}\text { Microbiologic eradication } \\
(\%)\end{array}$ & $\begin{array}{r}\text { Resistance at baseline } \\
(\%)\end{array}$ & $\begin{array}{r}\text { Emergent resistance } \\
(\%)\end{array}$ \\
\hline \multirow[t]{2}{*}{ Chastre, 2008 [39] } & Imipenem & 25 & 42.9 & 35.7 & 24.0 & 52.6 \\
\hline & Comparator & 28 & 80.0 & 65.0 & 0.0 & 35.7 \\
\hline \multirow{2}{*}{$\begin{array}{l}\text { Yanagihara, } 2005 \\
\text { [40] }\end{array}$} & Imipenem & 4 & & 50.0 & & \\
\hline & Comparator & 3 & & 0.0 & & \\
\hline \multirow[t]{2}{*}{ Joshi, 2006 [42] } & Imipenem & 17 & & 70.6 & & \\
\hline & Comparator & 18 & & 76.5 & & \\
\hline \multirow{2}{*}{$\begin{array}{l}\text { Romanelli, } 2006 \\
\text { [43] }\end{array}$} & Imipenem & 1 & 0.0 & 0.0 & & \\
\hline & Comparator & 1 & 0.0 & 0.0 & & \\
\hline \multirow[t]{2}{*}{ Shorr, 2005 [44] } & Imipenem & $18^{\dagger}$ & 72.0 & & & 5.6 \\
\hline & Comparator & 16 & 85.0 & & & 6.3 \\
\hline \multirow[t]{2}{*}{ Zanetti, 2003 [45] } & Imipenem & 32 & & & 15.6 & 28.1 \\
\hline & Comparator & 27 & & & 7.4 & 11.1 \\
\hline \multirow[t]{2}{*}{ West, 2003 [46] } & Imipenem & $17^{\dagger}$ & 41.2 & 29.4 & & \\
\hline & Comparator & 17 & 64.7 & 58.8 & & \\
\hline \multirow[t]{2}{*}{ Torres, 2000 [47] } & Imipenem & 12 & 66.0 & 25.0 & & 33.0 \\
\hline & Comparator & 14 & 71.0 & 50.0 & & 7.0 \\
\hline \multirow{2}{*}{$\begin{array}{l}\text { Bartoloni, } 1999 \\
\text { [48] }\end{array}$} & Imipenem & 3 & 66.6 & 66.7 & & \\
\hline & Comparator & 1 & 100.0 & 100.0 & & \\
\hline \multirow[t]{2}{*}{ Jaccard, 1998 [49] } & Imipenem & 24 & 50.0 & & 4.2 & 25.0 \\
\hline & Comparator & 21 & 90.5 & & 0.0 & 4.8 \\
\hline \multirow[t]{2}{*}{ Ho, 1997 [51] } & Imipenem & 2 & 50.0 & & & \\
\hline & Comparator & 3 & 100.0 & & & \\
\hline \multirow[t]{2}{*}{ Raad, 1996 [52] } & Imipenem & 1 & 0.0 & & & \\
\hline & Comparator & 4 & 75.0 & & & \\
\hline \multirow[t]{2}{*}{ Vic, 1996 [53] } & Imipenem & 1 & & 100.0 & & \\
\hline & Comparator & 19 & & 100.0 & & \\
\hline \multirow[t]{2}{*}{ Bohme, 1995 [54] } & Imipenem & 3 & 66.0 & 66.0 & & \\
\hline & Comparator & 0 & NA & NA & & \\
\hline \multirow[t]{2}{*}{ Siami, 1995 [55] } & Imipenem & 9 & & & & 77.8 \\
\hline & Comparator & 12 & & & & 41.7 \\
\hline \multirow{2}{*}{$\begin{array}{l}\text { Cometta, } 1994 \\
\text { [56] }\end{array}$} & Imipenem & 24 & & 55.6 & & 33.3 \\
\hline & Comparator & 23 & & 50.0 & & 56.5 \\
\hline \multirow[t]{2}{*}{ Fink, 1994 [57] } & Imipenem & 44 & & 25.0 & & 50.0 \\
\hline & Comparator & 47 & & 27.7 & & 28.0 \\
\hline \multirow[t]{2}{*}{ Norrby, 1993 [58] } & Imipenem & 14 & 42.1 & & & 42.9 \\
\hline & Comparator & 16 & 82.4 & & & 6.3 \\
\hline \multirow[t]{2}{*}{ Pooled rates } & Imipenem & 251 & 45.2 & 47.6 & 14.6 & 38.7 \\
\hline & Comparator & 270 & 74.9 & 52.8 & 2.5 & 21.9 \\
\hline
\end{tabular}

*Limited to studies reporting at least one of these outcomes; empty cells indicate that the corresponding data were not reported

${ }^{\dagger}$ Although the total pseudomonal isolates in the two arms of each analysis add up to the same number $(n=34)$, the distribution between the arms is different presumably due to reclassification of a single PA isolate from the levofloxacin to the imipenem arm, which occurred between the West [46] publication and the Shorr [44] analysis.

PA:Pseudomonas aeruginosa; NA: not applicable

\section{Comparator classes}

PA microbiological eradication rates in studies stratified based on antibiotic class of the comparator drug mirrored overall PA eradication rates (Table 3 ). The pooled rates of clinical success in trials utilizing beta- lactams and reporting this outcome $[39,43,44,46,48,49,51,52,54,56]$ were $39.9 \%$ (range $0.0 \%$ $72.0 \%)$ and $84.7 \%(0.0 \%-100.0 \%)$ in the imipenem and comparator groups, with corresponding microbiologic eradication rates $[39,40,42,43,46,48,53,54,56]$ of $52.7 \%$ 


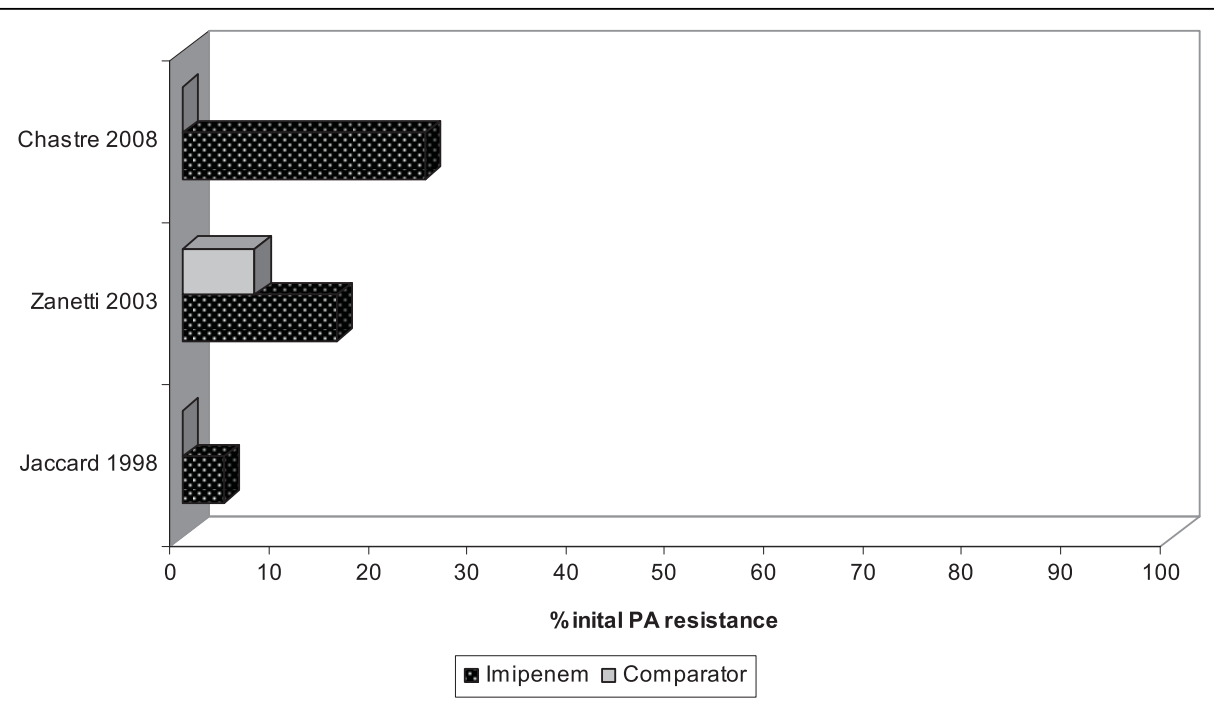

Figure 2 Proportion of initial reported $P$. aeruginosa resistance to imipenem and comparators graphed chronologically from 1994 to 2009. PA: Pseudomonas aeruginosa

(range $0.0 \%-70.6 \%$ ) for imipenem and $56.3 \%$ (range $0.0 \%-100.0 \%)$ for comparators. Three beta-lactam studies reported initial resistance rates $[39,45,49]$, and they were $14.6 \%$ (range $4.2 \%-24.0 \%$ ) and $2.5 \%$ (range $0.0 \%-7.4 \%$ ) for imipenem and comparator groups, respectively. Resistance emergence was reported in 6 studies $[39,44,45,49,56,58]$ in $31.3 \%$ (range 5.6\%-52.6\%) of imipenem and $20.1 \%$ (range $4.8 \%-56.5 \%$ ) of comparator group PA isolates. A pooled analysis of the subgroup of beta-lactam trials specifically comparing imipenem to another carbapenem revealed clinical success rates of $36.5 \%$ (range $0.0 \%-66.7 \%$ ) in the imipenem and $60.0 \%$ (range $0.0 \%-100.0 \%$ ) in the comparator carbapenem groups $[39,43,48]$, while the microbiologic eradication rates were $39.5 \%$ (range $0.0 \%-66.7 \%$ ) for imipenem and 53.8\% (range $0.0 \%-100.0 \%$ ) for the comparator carbapenems $[39,43,48,56]$. Only one carbapenem study reported initial resistance, which was detected in $24.0 \%$ of patients in the imipenem and $0.0 \%$ in the doripenem groups [39]. In the same study comparing doripenem to imipenem in patients with VAP, the rate of resistance emergence was $52.6 \%$ in the imipenem and $35.7 \%$ in the doripenem groups [39]. This is the only study where resistance emergence was defined explicitly, and denoted a decrease in susceptibility being a $4+-$ fold increase in the MIC [39]. Notably true resistance (defined as $\mathrm{MIC} \geq 8 \mu \mathrm{g} / \mathrm{mL}$ ) developed in $20 \%$ in the doripenem arm and $57 \%$ in the imipenem arm [39]. The only other carbapenem study reporting emergence of resistance noted this rate

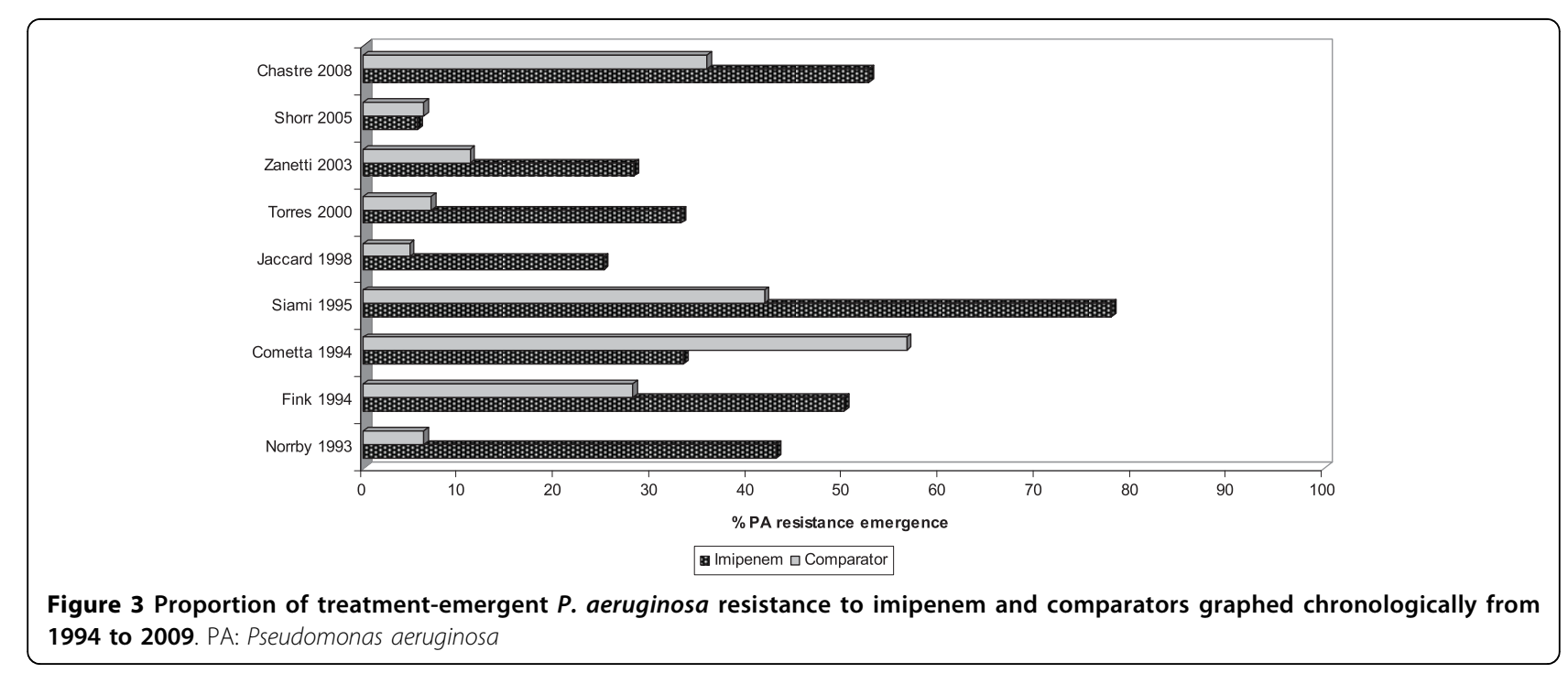


Table 3 Sensitivity analyses*

\begin{tabular}{|c|c|c|c|c|c|c|c|c|c|}
\hline \multirow[t]{2}{*}{ Subgroup } & \multirow[t]{2}{*}{$\begin{array}{l}\text { Study } \\
\text { arm }\end{array}$} & \multicolumn{2}{|l|}{ Clinical success } & \multicolumn{2}{|l|}{ Microbiologic eradication } & \multicolumn{2}{|c|}{$\begin{array}{l}\text { Resistance at } \\
\text { baseline }\end{array}$} & \multicolumn{2}{|c|}{ Emergent resistance } \\
\hline & & PA isolates (n) & $\begin{array}{l}\% \\
\text { (range) }\end{array}$ & PA isolates (n) & $\begin{array}{l}\% \\
\text { (range) }\end{array}$ & $\begin{array}{l}\text { PA } \\
\text { isolates } \\
\text { (n) }\end{array}$ & $\begin{array}{l}\% \\
\text { (range) }\end{array}$ & PA isolates (n) & $\begin{array}{l}\% \\
\text { (range) }\end{array}$ \\
\hline \multirow[t]{3}{*}{$\begin{array}{l}\text { Blinding } \\
\text { present }\end{array}$} & 1 & 15 & $\begin{array}{l}21.1 \\
(0.0- \\
42.1)\end{array}$ & 61 & $\begin{array}{l}47.8 \\
(25.0- \\
70.6)\end{array}$ & NR & & 67 & $\begin{array}{l}56.9 \\
(42.9- \\
77.8)\end{array}$ \\
\hline & C & 20 & $\begin{array}{l}78.7 \\
(75.0- \\
82.4)\end{array}$ & 65 & $\begin{array}{l}52.1 \\
(27.7- \\
76.5)\end{array}$ & NR & & 75 & $\begin{array}{l}25.3 \\
(6.3- \\
41.7)\end{array}$ \\
\hline & & {$[52,58]$} & & {$[42,57]$} & & & & {$[55,57,58]$} & \\
\hline \multicolumn{10}{|l|}{$\begin{array}{l}\text { Comparator } \\
\text { drug class }\end{array}$} \\
\hline \multirow[t]{3}{*}{$\beta$-lactam } & I & 108 & $\begin{array}{l}39.9 \\
(0.0- \\
72.0)\end{array}$ & 95 & $\begin{array}{l}52.7 \\
(0.0- \\
70.6)\end{array}$ & 81 & $\begin{array}{l}14.6 \\
(4.2- \\
24.0)\end{array}$ & 137 & $\begin{array}{l}31.3 \\
(5.6- \\
52.6)\end{array}$ \\
\hline & C & 107 & $\begin{array}{l}84.7 \\
(0.0- \\
100.0)\end{array}$ & 110 & $\begin{array}{l}56.3 \\
(0.0- \\
100.0)\end{array}$ & 76 & $\begin{array}{l}2.5 \\
(0.0- \\
7.4)\end{array}$ & 131 & $\begin{array}{l}20.1 \\
(4.8- \\
56.5)\end{array}$ \\
\hline & & {$[39,43,44,46,48,49,51,52,54,56]$} & & {$[39,40,42,43,46,48,53,54,56]$} & & {$[39,45,49]$} & & {$[39,44,45,49,56,58]$} & \\
\hline \multirow[t]{3}{*}{$\begin{array}{l}\text { Fluoro- } \\
\text { quinolone }\end{array}$} & 1 & 47 & $\begin{array}{l}59.7 \\
(41.2- \\
72.0)\end{array}$ & 95 & $\begin{array}{l}26.5 \\
(25.0- \\
29.4)\end{array}$ & NR & & 83 & $\begin{array}{l}41.6 \\
(5.6- \\
77.8)\end{array}$ \\
\hline & C & 47 & $\begin{array}{l}73.6 \\
(64.7- \\
85.0)\end{array}$ & 110 & $\begin{array}{l}45.5 \\
(27.7- \\
58.8)\end{array}$ & NR & & 89 & $\begin{array}{l}20.7 \\
(6.3- \\
41.7)\end{array}$ \\
\hline & & {$[44,46,47]$} & & {$[46,47,57]$} & & & & {$[44,47,55,57]$} & \\
\hline \multirow[t]{3}{*}{$\begin{array}{l}\text { Nosocomial } \\
\text { pneumonia }\end{array}$} & 1 & 72 & $\begin{array}{l}55.5 \\
(41.2- \\
72.0)\end{array}$ & 71 & $\begin{array}{l}40.2 \\
(25.0- \\
50.0)\end{array}$ & 57 & $\begin{array}{l}19.9 \\
(4.2- \\
24.0)\end{array}$ & 87 & $\begin{array}{l}29.8 \\
(5.6- \\
52.6)\end{array}$ \\
\hline & C & 75 & $\begin{array}{l}75.2 \\
(64.7- \\
85.0)\end{array}$ & 77 & $\begin{array}{l}62.6 \\
(50.0- \\
76.5)\end{array}$ & 55 & $\begin{array}{l}3.7 \\
(0.0- \\
7.4)\end{array}$ & 85 & $\begin{array}{l}15.0 \\
(6.3- \\
35.7)\end{array}$ \\
\hline & & {$[39,44,46,47]$} & & {$[39,42,46,47]$} & & {$[39,45]$} & & {$[39,44,45,47]$} & \\
\hline \multirow[t]{3}{*}{$\begin{array}{l}\text { VAP } \\
\text { subgroup }\end{array}$} & I & & $\begin{array}{l}60.3 \\
(41.2- \\
72.0)\end{array}$ & & $\begin{array}{l}30.4 \\
(25.0- \\
35.7)\end{array}$ & 25 & $\begin{array}{l}24.0 \\
\text { (NA) }\end{array}$ & 55 & $\begin{array}{l}30.4 \\
(5.6- \\
52.6)\end{array}$ \\
\hline & C & & $\begin{array}{l}78.7 \\
(71.0- \\
85.0)\end{array}$ & & $\begin{array}{l}57.5 \\
(50.0- \\
65.0)\end{array}$ & 28 & $\begin{array}{l}0.0 \\
(\mathrm{NA})\end{array}$ & 58 & $\begin{array}{l}16.3 \\
(6.3- \\
35.7)\end{array}$ \\
\hline & & {$[39,44,47]$} & & {$[39,46]$} & & [39] & & {$[39,44,47]$} & \\
\hline \multirow[t]{3}{*}{$\begin{array}{l}\text { North } \\
\text { America only }\end{array}$} & I & 36 & $\begin{array}{l}37.7 \\
(0.0- \\
72.0)\end{array}$ & 78 & $\begin{array}{l}41.7 \\
(25.0- \\
70.6)\end{array}$ & $N R$ & & 71 & $\begin{array}{l}44.4 \\
(5.6- \\
77.8)\end{array}$ \\
\hline & C & 37 & $\begin{array}{l}74.9 \\
(64.0- \\
85.0)\end{array}$ & 82 & $\begin{array}{l}54.3 \\
(27.7- \\
76.5)\end{array}$ & NR & & 75 & $\begin{array}{l}25.3 \\
(6.3- \\
41.7)\end{array}$ \\
\hline & & {$[44,46,52]$} & & {$[42,46,57]$} & & & & {$[44,55,57]$} & \\
\hline
\end{tabular}

*Numbers in brackets represent corresponding references

PA: Pseudomonas aeruginosa, I: imipenem, C: comparator, NR: not reported, NA: not applicable, VAP: ventilator-associated pneumonia

to be $33.3 \%$ in the imipenem and $56.5 \%$ in the meropenem groups [56]. Finally, in the studies comparing imipenem to treatment with a fluoroquinolone, imipenem demonstrated a clinical success rate of 59.7\% (range 41.2\%-72.0\%), while that for the comparators was 73.6\% (range 64.7\%-85.0\%) [44,46,47]. Microbiologic eradication rates were $26.5 \%$ (range $25.0 \%-29.4 \%$ ) for imipenem compared with $45.5 \%$ (range $27.7 \%-58.8 \%$ ) in the comparator groups $[46,47,57]$. While baseline resistance rates were not reported in any of the fluoroquinolone studies, resistance emerged at the rates of $41.6 \%$ (range 5.6\%-77.8\%) in the imipenem and 20.7\% (range 6.3\%-41.7\%) in the comparator fluoroquinolone groups $[44,47,55,57]$. 


\section{Nosocomial pneumonia}

In 7 studies enrolling exclusively NP patients, the results were similar to the overall findings [39,41,42,44-47] (Table 3). Clinical success in the imipenem arms was $55.5 \%$ (range $41.2 \%-72.0 \%$ ) and in the comparator arms 75.2\% (range 64.7\%-85.0\%) [39,44,46,47]. Microbiologic eradication rates were $40.2 \%$ (range $25.0 \%-50.0 \%$ ) in the imipenem and $62.6 \%$ (range $50.0 \%-76.5 \%$ ) in the comparator groups $[39,42,46,47]$. In the 2 studies reporting baseline resistance this rate was $19.9 \%$ (range $4.2 \%$ $24.0 \%$ ) in the imipenem and $3.7 \%$ (range $0.0 \%-7.4 \%$ ) in the comparator groups $[39,45]$. Four studies in this subgroup reported resistance emergence, and these pooled rates were $29.8 \%$ (range $5.6 \%-52.6 \%$ ) in the imipenem and $15.0 \%$ (range $6.3 \%-35.7 \%$ ) in the comparator groups $[39,44,45,47]$. A further look at VAP patients only revealed similar rates of $60.3 \%$ (range $41.2 \%-72.0 \%$ ) and $78.7 \%$ (range $71.0 \%-85.0 \%$ ) imipenem and comparator clinical success rates, respectively [39,44,47], while the corresponding microbiologic eradication rates for imipenem and comparators were $30.4 \%$ (range $25.0 \%-35.7 \%$ ) and $57.5 \%$ (range 50.0\%-65.0\%) [39,46].

\section{Geographic location}

The final sensitivity analysis was confined to the studies conducted only in North America $[42,44,46,50,52,55,57]$. In the 3 studies in this group reporting clinical success, the pooled rates of clinical success were $37.7 \%$ (range $0.0 \%-72.0 \%$ ) and $74.9 \%$ (range 64.0\%-85.0\%) for the imipenem and comparator groups, respectively $[44,46,52]$. The corresponding microbiologic eradication rates were $41.7 \%$ (range $25.0 \%-70.6 \%$ ) in the imipenem and $54.3 \%$ (range $27.7 \%-76.5 \%)$ in the comparator groups $[42,46,57]$. While none of the North American studies reported baseline resistance rates, resistance emerged in $44.4 \%$ (range 5.6\%-77.8\%) of imipenem and 25.3\% (range $6.3 \%-41.7 \%)$ of comparator group isolates $[44,55,57]$.

\section{Discussion}

The current systematic review confirms clinical experience that many PA isolates are likely to be resistant to imipenem at the initiation of treatment and, importantly, are likely to develop treatment-emergent resistance. Not only does PA account for $12 \%$ of all reported pathogens in pneumonia, $14.6 \%$ of all PA isolates exhibit resistance to imipenem at the initiation of treatment, and an additional $38.7 \%$ develop this during the course of treatment with imipenem. For comparator interventions, these rates are directionally lower, albeit still substantial, with $2.5 \%$ initial and $21.9 \%$ emergent resistance. While directionally slightly higher for both imipenem and comparator arms in the trials employing blinding, these general rates persisted across all sensitivity analyses.
As antibiotic resistance continues to escalate among both gram-positive and gram-negative pathogens [1,3-5], for PA specifically, a recent survey from the National Nosocomial Infections Surveillance Network [4] reported year 2003 PA resistance rates of approximately $32 \%, 20 \%$ and $30 \%$ to third generation cephalosporins, imipenem and quinolones, respectively, representing $20 \%, 15 \%$ and $9 \%$ growth, respectively, over the average resistance rates observed between 1998 and 2002 [4]. The importance of this development cannot be overstated for several reasons. First, it is clear that, similar to other resistant infections, multidrug resistant PA confers worsenes hospital outcomes, including increased mortality, prolonged length of stay and a rise in costs [59-61]. Second, and key to these outcomes at least in part, is the fact that a patient infected with a resistant pathogen is far more likely to be treated with an inappropriate initial antibiotic (one to which the isolate does not exhibit sensitivity in vitro) than with an appropriate one, a choice that approximately doubles the patient's risk of death $[9,10]$. Third, the rapid evolution of antimicrobial resistance is outpacing efforts to develop and manufacture newer therapies that are effective against new pathogens [62,63]. For all these reasons, and most importantly to improve patient-level outcomes, the patterns of antimicrobial resistance remain critical to study, and this current effort adds to the epidemiologic and microbiology-based knowledge of the burden of PA resistance to imipenem.

The rates of imipenem resistance among PA we uncovered were higher than the $20 \%$ reported by the NNIS in year 2003; ours approached $15 \%$ at baseline and developed on treatment in a further $39 \%$ of the isolates [4]. The differences between the two sources most likely represent differences in populations, in case definitions and in sampling methods. Although neither source is completely generalizable to real-world practice, (trials usually represent a highly select population and the composition of the NNIS hospitals is not disclosed and may not be representative of the US institutions overall) both sources confirm that the problem is grave. Interestingly, similar to the NNIS data, we observed an increase in the prevalence of baseline, but not emergent Pseudomonal imipenem resistance over time (Figure 1).

Our study has additionally documented substantial rates of emergent PA resistance while on treatment, particularly with imipenem. This result echoes the data reported in the meta-analysis by Siempos and colleagues, where development of resistance by PA during treatment for nosocomial pneumonia was higher in patients on carbapenems (mainly imipenem) than other antimicrobials, and that carbapenems were associated with lower treatment success when compared to other antimicrobials [64]. 
Aside from lending credence to clinical gestalt and confirming epidemiologic observations, our study further suggested that there is an opportunity to use ongoing pooled analyses of clinical data to understand antibiotic resistance issue as an adverse event. Because no individual study is likely to be powered to detect significant rates of baseline or emergent resistance, pharmacoepidemiologic surveillance methods should be advocated to quantify significant trends in this outcome. These techniques can be used as validation strategies for data obtained in epidemiologic and microbiology-based studies. Furthermore, our data point to the need to use integrated databases that include pharmacy and laboratory data as well for ongoing monitoring of antimicrobial resistance among specific organisms, such as PA.

Our study had a number of limitations, most of them driven by the limitations of either design or reporting of the primary trials. First, not all studies allowed us to extract data pertaining only to pneumonia patients, and therefore a small proportion of the overall aggregate results does not pertain to this disease. To counterbalance this issue, we performed a sensitivity analysis among patients with only nosocomial pneumonia, and the results in this group were not substantively different from those in the overall population. Second, despite the aggregate sample size of over 4,000 subjects with pneumonia, the subgroup growing out Pseudomonal pathogens was small, accounting for $12 \%$ of all cases. Furthermore, since not all endpoints of interest were reported in every study, the number of PA isolates continued to drift lower in specific analyses, lending limited power for drawing firm conclusions. For this reason, and due to inherent limitation of the data (i.e., PA was never the primary focus of the study) we did not attempt to perform statistical testing. Nevertheless, the fact that most sensitivity analyses resulted in similar proportions of resistance detection lends further credibility to the numbers. It is worth underscoring that some of the ranges of clinical and microbiologic response rates went from $0.0 \%$ to $100.0 \%$ (Tables 2,3 ), the width of the range ostensibly reducing the usefulness of our observation. However, we must point out that four of the five studies reporting these rates each included only one pseudomonal isolate [43,48,51-53], making these estimates neither clinically nor statistically meaningful. Excluding these rates from the clinical success endpoint, for example, would result in the range from $41.2 \%$ to $72.0 \%$ in the imipenem and from $64.7 \%$ to $90.5 \%$ for the comparator groups (Table 2). Third, only a handful of the trials employed blinding to reduce bias, and in those trials the resistance rates were directionally slightly higher than in ones without blinding. Despite these limitations, this body of evidence further served to call attention to the alarming rates of antimicrobial resistance among PA in general, and to imipenem specifically.

\section{Conclusions}

In summary, pooling observations from clinical trials occurring over a 15-year period we computed the cumulative PA resistance rate to imipenem to be in the range of $50 \%$, persisting in many sensitivity analyses. The $15 \%$ resistance rate at baseline further stresses the importance of risk stratification at bedside and the need to employ early appropriate therapy to improve patient outcomes. The additional 39\% resistance development on treatment is also sobering, implying that 1) clinicians employing early broad spectrum coverage need to pay exquisite attention to prompt de-escalation if such coverage is not needed, and 2) researchers need to focus on developing novel therapies whose mechanisms of action may be less subject to the microbial adaptation apparatus. In all, our data add to the epidemiologic alarm of PA resistance and help further sound the call to arrive at strategies that balance patient outcomes with the growing public health threat of antimicrobial resistance.

\section{Acknowledgements}

No one other than the authors contributed substantially to the study or the manuscript.

\section{Author details}

${ }^{1} S c h o o l$ of Public Health and Health Sciences, University of Massachusetts, Amherst, MA, USA. ${ }^{2}$ EviMed Research Group, LLC, Goshen, MA, USA. ${ }^{3}$ OrthoMcNeil Janssen Scientific Affairs, LLC, Raritan, NJ, USA. ${ }^{4}$ Division of Pulmonary and Critical Care Medicine, Washington Hospital Center, Washington, DC, USA.

\section{Authors' contributions}

MDZ contributed to study conception and design, and analysis and interpretation of data; was involved in drafting the manuscript and revising it critically for important intellectual content; and gave final approval of the version to be published. JC contributed to study conception and design and acquisition of data; was involved in revising the manuscript critically for important intellectual content; and gave final approval of the version to be published. SHM contributed to conception and design, and acquisition of data; was involved in revising the manuscript critically for important intellectual content; and gave final approval of the version to be published. AMR made substantial contributions to conception and design, acquisition and interpretation of data; was involved in drafting the manuscript; and gave final approval of the version to be published. AFS have made substantial contributions to conception and design, analysis and interpretation of data; was involved in revising the manuscript critically for important intellectual content; and gave final approval of the version to be published.

\section{Competing interests}

This study was funded by a grant from Ortho-McNeil Janssen Scientific Affairs, LLC, Raritan, NJ, USA, the manufacturer of doripenem.

Received: 22 February 2010 Accepted: 26 August 2010

Published: 26 August 2010

\section{References}

1. Klein E, Smith DL, Laxminarayan R: Hospitalizations and deaths caused by methicillin-resistant Staphylococcus aureus, United States, 1999-2005. Emerg Infect Dis 2007, 13:1840-1846. 
2. Ramsey AM, Zilberberg MD: Secular trends in vancomycin-resistant Enterococcus hospitalization in the US, 2000-2006. Infect Control Hosp Epidemiol 2009, 30:184-6.

3. Zilberberg MD, Shorr AF, Kollef MH: Growth and geographic variation in hospitalizations with resistant infections, United States, 2000-2005. Emerg Infect Dis 2008, 14(11):1756-8.

4. National Nosocomial Infections Surveillance (NNIS) System Report. Am J Infect Control 2004, 32:470.

5. Obritsch MD, Fish DN, MacLaren R, Jung R: National surveillance of antimicrobial resistance in Pseudomonas aeruginosa isolates obtained from intensive care unit patients from 1993 to 2002. Antimicrob Agents Chemother 2004, 48:4606-10.

6. Hospital-Acquired Pneumonia Guideline Committee of the American Thoracic Society and Infectious Diseases Society of America: Guidelines for the management of adults with hospital-acquired pneumonia, ventilator-associated pneumonia, and healthcare-associated pneumonia. Am J Respir Crit Care Med 2005, 171:388-416.

7. Iregui M, Ward S, Sherman G, Fraser VJ, Kollef MH: Clinical importance of delays in the initiation antibiotic treatment for ventilator-associated pneumonia. Chest 2002, 122:262-268.

8. Alvarez-Lerma F: ICU-acquired Pneumonia Study Group. Modification of empiric antibiotic treatment in patients with pneumonia acquired in the intensive care unit. Intensive Care Med 1996, 22:387-394.

9. Micek ST, Lloyd AE, Ritchie DJ, Reichley RM, Fraser VJ, Kollef MH: Pseudomonas aeruginosa bloodstream infection: the importance of appropriate initial antimicrobial treatment. Antimicrob Agents Chemother 2005, 49(4):1306-11.

10. Micek ST, Kollef KE, Reichley RM, Roubinian N, Kollef MH: Health caseassociated pneumonia annd community-acquired pneumonia: a singlecenter experience. Antimicrob Agents Chemother 2007, 51(10):3568-73.

11. Gales A, Jones R, Turnidge J, Rennie R, Ramphal R: Characterization of Pseudomonas aeruginosa Isolates: Occurrence Rates, Antimicrobial Susceptibility Patterns, and Molecular Typing in the Global SENTRY Antimicrobial Surveillance Program, 1997-1999. Clin Infect Dis 2001, 32(Suppl 2):S146-55.

12. Hanberger H, Garcia-Rodriguez JA, Gobernado M, Goossens H, Nilsson LE, Struelens MJ: Antibiotic susceptibility among aerobic gram-negative bacilli in intensive care units in 5 European countries. French and Portuguese ICU Study Groups. JAMA 1999, 281(1):67-71.

13. Beaucaire G: Evaluation of the efficacy and safety of isepamicin compared with amikacin in the treatment of nosocomial pneumonia and septicaemia. J Chemother 1995, 7(Suppl 2):165-73

14. Gulberg V, Deibert $P$, Ochs A, Rossle M, Gerbes AL: Prevention of infectious complications after transjugular intrahepatic portosystemic shunt in cirrhotic patients with a single dose of ceftriaxone. Hepatogastroenterology 1999, 46(26):1126-30.

15. Leblebicioglu H, Rosenthal VD, Arikan OA, Ozgültekin A, Yalcin AN, Koksal I, Usluer G, Sardan YC, Ulusoy S: Turkish Branch of INICC. Device-associated hospital-acquired infection rates in Turkish intensive careunits. Findings of the International Nosocomial Infection Control Consortium (INICC). J Hosp Infect 2007, 65(3):251-7.

16. Gales AC, Sader HHS, Jones RN: Respiratory tract pathogens isolated from patients hospitalized with suspected pneumonia in Latin America: frequency of occurrence and antimicrobial susceptibility profile: results from the SENTRY Antimicrobial Surveillance Program (1997-2000). Diagn Microbiol Infect Dis 2002, 44(3):301-11.

17. Sader HS, Jones RN, Gales AC, Winokur P, Kugler KC, Pfaller MA, Doern GV: Antimicrobial susceptibility patterns for pathogens isolated from patients in Latin American medical centers with a diagnosis of pneumonia: analysis of results from the SENTRY Antimicrobial Surveillance Program (1997). SENTRY Latin America Study Group. Diagn Microbiol Infect Dis 1998, 32(4):289-301.

18. García-Sáenz JA, Martín M, Casado A, Pérez-Segura P, Manrique I, Flores L, Macias JA, Cámara JC, Perezagua C, Díaz-Rubio E: Immediate vs. delayed imipenem treatment in cancer patients with profound neutropenia induced by high-dose chemotherapy: results of a randomized study. Rev Esp Quimioter 2002, 15(3):257-63.

19. Torres-Tortosa M, Arrizabalaga J, Villanueva JL, Gálvez J, Leyes M, Valencia ME, Flores J, Peña JM, Pérez-Cecilia E, Quereda C: Grupo Andaluz para el estudio de las Enfermedades Infecciosas; Grupo de estudio de SIDA of the Sociedad Española de Enfermedades Infecciosas y
Microbiología Clínica. Prognosis and clinical evaluation of infection caused by Rhodococcus equi in HIV-infected patients: a multicenter study of 67 cases. Chest 2003, 123(6):1970-6.

20. Saballs M, Pujol M, Tubau F, Peña C, Montero A, Domínguez MA, Gudiol F, Ariza J: Rifampicin/imipenem combination in the treatment of carbapenem-resistant Acinetobacter baumannii infections. J Antimicrob Chemother 2006, 58(3):697-700.

21. Maskin B, Fontán PA, Spinedi EG, Gammella D, Badolati A: Evaluation of endotoxin release and cytokine production induced by antibiotics in patients with Gram-negative nosocomial pneumonia. Crit Care Med 2002, 30(2):349-54.

22. Feldman C, White H, O'Grady J, Flitcroft A, Briggs A, Richards G: An open, randomised, multi-centre study comparing the safety and efficacy of sitafloxacin and imipenem/cilastatin in the intravenous treatment of hospitalized patients with pneumonia. Int J Antimicrob Agents 2001, 17(3):177-88

23. Polk HC Jr, Livingston DH, Fry DE, Malangoni MA, Fabian T, Trachtenberg LS, Gardner SA, Kesterson L, Cheadle WG: Treatment of pneumonia in mechanically ventilated trauma patients. Results of a prospective trial. Arch Surg 1997, 132(10):1086-92.

24. McKindley DS, Boucher BA, Hess MM, Croce MA, Fabian TC Pharmacokinetics of aztreonam and imipenem in critically ill patients with pneumonia. Pharmacotherapy 1996, 16(5):924-31.

25. Young LS, Sabel AL, Price CS: Epidemiologic, clinical, and economic evaluation of an outbreak of clonal multidrug-resistant Acinetobacter baumannii infection in a surgical intensive care unit. Infect Control Hosp Epidemiol 2007, 28(11):1247-54

26. Corbella X, Ariza J, Ardanuy C, Vuelta M, Tubau F, Sora M, Pujol M, Gudiol F: Efficacy of sulbactam alone and in combination with ampicillin in nosocomial infections caused by multiresistant Acinetobacter baumannii. J Antimicrob Chemother 2000, 45(5):712-3.

27. Caldwell JW, Singh S, Johnson RH: Clinical and economic evaluation of subsequent infection following intravenous ciprofloxacin or imipenem therapy in hospitalized patients with severe pneumonia. J Antimicrob Chemother 1999, 43(Suppl A):115

28. Levin AS, Barone AA, Penço J, Santos MV, Marinho IS, Arruda EA, Manrique El, Costa SF: Intravenous colistin as therapy for nosocomial infections caused by multidrug-resistant Pseudomonas aeruginosa and Acinetobacter baumannii. Clin Infect Dis 2002, 35(7):901-2.

29. Giamarellos-Bourboulis EJ, Mega A, Pavleas I, Archontoulis N, Rigas K, Vernikos P, Giamarellou H, Thomopoulos G: Impact of carbapenem administration on systemic endotoxemia in patients with severe sepsis and Gram-negative bacteremia. J Chemother 2006, 18(5):502-6.

30. Kuo Bl, Fung CP, Liu CY: Meropenem versus imipenem/cilastatin in the treatment of sepsis in Chinese patients. Zhonghua Yi Xue Za Zhi (Taipei) 2000, 63(5):361-7.

31. Cakmakci M, Stern A, Schilling J, Christen D, Roggo A, Geroulanos S: Randomized comparative trial of imipenem/cilastatin versus aminoglycoside plus amoxycillin plus clindamycin in the treatment of severe intra- and post-operative infections. Drugs Exp Clin Res 1993, 19(5):223-7.

32. Link $H$, Maschmeyer $G$, Meyer $P$, Hiddemann $W$, Stille $W$, Helmerking $M$, Adam D: Interventional antimicrobial therapy in febrile neutropenic patients. Study Group of the Paul Ehrlich Society for Chemotherapy. Ann Hematol 1994, 69(5):231-43

33. Egerer G, Goldschmidt H, Salwender H, Hegenbart U, Ehrhard I, Haas R, Ho AD: Efficacy of continuous infusion of ceftazidime for patients with neutropenic fever after high-dose chemotherapy and peripheral blood stem cell transplantation. Int J Antimicrob Agents 2000, 15(2):119-23.

34. Sakka SG, Glauner AK, Bulitta JB, Kinzig-Schippers M, Pfister W, Drusano GL, Sörgel F: Population pharmacokinetics and pharmacodynamics of continuous versus short-term infusion of imipenem-cilastatin in critically ill patients in a randomized, controlled trial. Antimicrob Agents Chemother 2007, 51(9):3304-10.

35. Alvarez-Lerma F, Alvarez B, Luque P, Ruiz F, Dominguez-Roldan JM, Quintana E, Sanz-Rodriguez C: ADANN Study Group. Empiric broadspectrum antibiotic therapy of nosocomial pneumonia in the intensive care unit: a prospective observational study. Crit Care 2006, 10(3):R78.

36. Shorr AF, Susla GB, Kollef MH: Quinolones for treatment of nosocomia pneumonia: a meta-analysis. Clin Infect Dis 2005, 40(Suppl 2):S115-22. 
37. Tennenberg AM, Davis NB, Wu SC, Kahn J: Pneumonia due to Pseudomonas aeruginosa: the levofloxacin clinical trials experience. Curr Med Res Opin 2006, 22(5):843-50.

38. Snydman D, Fink M, Niederman M, Reinhart $H$ : Treatment of severe pneumonia in hospitalised patients. Results of a multicentre trial comparing i.v. ciprofloxacin with imipenem/cilastatin. Drugs 1995, 49(Suppl 2):439-41.

39. Chastre J, Wunderink RR, Prokocimer P, Lee M, Kaniga K, Friedland I: Efficacy and safety of intravenous infusion of doripenem versus imipenem in ventilator-associated pneumonia: A multicenter, randomized study. Crit Care Med 2008, 36(4):1089-96.

40. Yanagihara K, Fukuda Y, Seki M, Izumikawa K, Higashiyama Y, Miyazaki Y, Hirakata Y, Tomono K, Mizuta Y, Tsukamoto K, Kohno S: Clinical comparative study of sulbactam/ampicillin and imipenem/cilastatin in elderly patients with community-acquired pneumonia. Intern Med 2006, 45(17):995-9.

41. Schmitt DV, Leitner $E$, Welte $T$, Lode H: Piperacillin/tazobactam vs imipenem/cilastatin in the treatment of nosocomial pneumonia-a double blind prospective multicentre study. Infection 2006, 34(3):127-34.

42. Joshi M, Metzler M, McCarthy M, Olvey S, Kassira W, Cooper A: Comparison of piperacillin/tazobactam and imipenem/cilastatin, both in combination with tobramycin, administered every $6 \mathrm{~h}$ for treatment of nosocomial pneumonia. Respir Med 2006, 100(9):1554-65.

43. Romanelli G, Cravarezza P, Pozzi A, Franchino L, Ravizzola G, Zulli R, Donati $P$, Prometti $P$, Grassi V: Carbapenems in the treatment of severe community-acquired pneumonia in hospitalized elderly patients: a comparative study against standard therapy. J Chemother 2002, 14(6):609-17.

44. Shorr AF, Zadeikis N, Jackson WL, Ramage AS, Wu SC, Tennenberg AM, Kollef $\mathrm{MH}$ : Levofloxacin for treatment of ventilator-associated pneumonia: a subgroup analysis from a randomized trial. Clin Infect Dis 2005, 41(3):414-5, author reply 415-6.

45. Zanetti G, Bally F, Greub G, Garbino J, Kinge T, Lew D, Romand JA, Bille J, Aymon D, Stratchounski L, Krawczyk L, Rubinstein E, Schaller MD, Chiolero R, Glauser MP, Cometta A: Cefepime Study Group,. Cefepime versus imipenem-cilastatin for treatment of nosocomial pneumonia in intensive care unit patients: a multicenter, evaluator-blind, prospective, randomized study. Antimicrob Agents Chemother 2003, 47(11):3442-7.

46. West M, Boulanger BR, Fogarty C, Tennenberg A, Wiesinger B, Oross M, Wu SC, Fowler C, Morgan N, Kahn JB: Levofloxacin compared with imipenem/cilastatin followed by ciprofloxacin in adult patients with nosocomial pneumonia: a multicenter, prospective, randomized, openlabel study. Clin Ther 2003, 25(2):485-506.

47. Torres A, Bauer TT, León-Gil C, Castillo F, Alvarez-Lerma F, Martínez-Pellús A, Leal-Noval SR, Nadal P, Palomar M, Blanquer J, Ros F: Treatment of severe nosocomial pneumonia: a prospective randomised comparison of intravenous ciprofloxacin with imipenem/cilastatin. Thorax 2000 55(12):1033-9.

48. Bartoloni A, Strohmeyer M, Corti G, Buonomini MI, Franchino L, Romanelli G, Moretti AM, De Vizzi GB, Petraglia A, Mancini P, Atzeni R, Fogliani V, Giura R, Paradisi F: Multicenter randomized trial comparing meropenem (1.5 g daily) and imipenem/cilastatin ( $2 \mathrm{~g}$ daily) in the hospital treatment of community-acquired pneumonia. Drugs Exp Clin Res 1999, 25(6):243-52.

49. Jaccard C, Troillet N, Harbarth S, Zanetti G, Aymon D, Schneider R, Chiolero R, Ricou B, Romand J, Huber O, Ambrosetti P, Praz G, Lew D, Bille J, Glauser MP, Cometta A: Prospective randomized comparison of imipenem-cilastatin and piperacillin-tazobactam in nosocomial pneumonia or peritonitis. Antimicrob Agents Chemother 1999, 43(3):726.

50. Marra F, Reynolds R, Stiver G, Bryce E, Sleigh K, Frighetto L, MacDougall C, Jewesson P: Piperacillin/tazobactam versus imipenem: a double-blind, randomized formulary feasibility study at a major teaching hospital. Diagn Microbiol Infect Dis 1998, 31(2):355-68.

51. Ho A, Leung R, Lai CK, Chan TH, Chan CH: Hospitalized patients with community-acquired pneumonia in Hong Kong: a randomized study comparing imipenem/cilastatin and ceftazidime. Respiration 1997, 64(4):303.

52. Raad II, Whimbey EE, Rolston KV, Abi-Said D, Hachem RY, Pandya RG, Ghaddar HM, Karl CL, Bodey GP: A comparison of aztreonam plus vancomycin and imipenem plus vancomycin as initial therapy for febrile neutropenic cancer patients. Cancer 1996, 77(7):1386-94.
53. Vic P, Ategbo S, Turck D, Husson MO, Tassin E, Loeuille GA, Deschildre A, Druon D, Elian JC, Arrouet-Lagandre C, Farriaux JP: Tolerance, pharmacokinetics and efficacy of once daily amikacin for treatment of Pseudomonas aeruginosa pulmonary exacerbations in cystic fibrosis patients. Eur J Pediatr 1996, 155(11):948-53.

54. Böhme A, Just-Nübling G, Bergmann L, Shah PM, Stille W, Hoelzer D: A randomized study of imipenem compared to cefotaxime plus piperacillin as initial therapy of infections in granulocytopenic patients. Infection 1995, 23(6):349-55

55. Siami GA, Wilkins WT, Bess DT, Christman JW: Comparison of ciprofloxacin with imipenem in the treatment of severe pneumonia in hospitalised geriatric patients. Drugs 1995, 49(Suppl 2):436-8.

56. Cometta A, Baumgartner JD, Lew D, Zimmerli W, Pittet D, Chopart P, Schaad U, Herter C, Eggimann P, Huber O, Ricou B, Suter P, Auckenthaler R, Chiorela R, Bille J, Scheidegger C, Frei R, Glauser MP: Prospective randomized comparison of imipenem monotherapy with imipenem plus netilmicin for treatment of severe infections in nonneutropenic patients. Antimicrob Agents Chemother. 1994, 38(6):1309-13.

57. Fink MP, Snydman DR, Niederman MS, Leeper KV Jr, Johnson RH, Heard SO, Wunderink RG, Caldwell JW, Schentag JJ, Siami GA, Zameck RL, Haverstock DC, Reinhart HH, Echols RM: Severe Pneumonia Study Group. Treatment of severe pneumonia in hospitalized patients: results of a multicenter, randomized, double-blind trial comparing intravenous ciprofloxacin with imipenem-cilastatin. The Severe Pneumonia Study Group. Antimicrob Agents Chemother 1994, 38(3):547-57.

58. Norrby SR, Finch RG, Glauser M: Monotherapy in serious hospital-acquired infections: a clinical trial of ceftazidime versus imipenem/cilastatin. European Study Group. J Antimicrob Chemother 1993, 31(6):927-37.

59. Aloush V, Navon-Venezia S, Seigman-lgra Y, Cabili S, Carmeli Y: Multidrugresistant Pseudomonas aeruginosa: risk factors and clinical impact. Antimicrob Agents Chemother 2006, 50(1):43-8.

60. Harris AD, Castro J, Sheppard DC, Carmeli Y, Samore MH: Risk factors for nosocomial candiduria due to Candida glabrata and Candida albicans. Clin Infect Dis 1999, 29(4):926-8.

61. Lautenbach E, Weiner MG, Nachamkin I, Bilker WB, Sheridan A, Fishman NO: Imipenem resistance among pseudomonas aeruginosa isolates: risk factors for infection and impact of resistance on clinical and economic outcomes. Infect Control Hosp Epidemiol 2006, 27(9):893-900.

62. Spellberg B, Powers JH, Brass EP, Miller LG, Edwards JE Jr: Trends in antimicrobial drug development: implications for the future. Clin Infect Dis 2004, 38(9):1279-86.

63. Fox JL: The business of developing antibacterials. Nat Biotechnol 2006, 24(12):1521-8.

64. Siempos II, Vardakas KZ, Manta KG, Falagas ME: Carbapenems for the treatment of immunocompetent adult patients with nosocomial pneumonia. Eur Respir J 2007, 29:548-60.

\section{Pre-publication history}

The pre-publication history for this paper can be accessed here: http://www.biomedcentral.com/1471-2466/10/45/prepub

doi:10.1186/1471-2466-10-45

Cite this article as: Zilberberg et al:: Imipenem resistance of Pseudomonas in pneumonia: a systematic literature review. BMC Pulmonary Medicine 2010 10:45.

\section{Submit your next manuscript to BioMed Central and take full advantage of:}

- Convenient online submission

- Thorough peer review

- No space constraints or color figure charges

- Immediate publication on acceptance

- Inclusion in PubMed, CAS, Scopus and Google Scholar

- Research which is freely available for redistribution 